
\title{
25 Research Square \\ Epidemiological Characteristics of Rubella in Beijing Haidian District of China, 2005 - 2020
}

\section{Susu Yu}

Jinan University

Xinyue Peng

Jinan University

\section{Fan Wu}

Jinan University

Jiani Yang

Jinan University

Cheng Zhou

Jinan University

Luyun Zhang

Jinan University

Hui Lin

Guangdong Provincial People's Hospital \& Guangdong Academy of Medical Sciences

\section{Zhisheng Wei}

Four Seasons Hospital, Haidian District, Beijing, China

Wenjuan Zhang ( $\nabla$ zwj2080@126.com)

Jinan University

\section{Research Article}

Keywords: Rubella, Respiratory infections, Prevalence, Epidemiology

Posted Date: June 3rd, 2021

DOI: https://doi.org/10.21203/rs.3.rs-565312/v1

License: (c) (1) This work is licensed under a Creative Commons Attribution 4.0 International License.

Read Full License 


\section{Abstract}

Background: This study aimed to investigate the epidemiological characteristics of rubella in Beijing Haidian District of China, from 2005 to 2020, providing scientific basis for controlling the prevalence of rubella and the congenital rubella syndrome (CRS).

Methods: Data were collected via the legal infectious disease report cards from medical institutions in Beijing Haidian District during 2005 to 2020. The descriptive epidemiological methods plus statistic analysis were used to analyze the distribution of rubella in terms of population, time and region.

Results: In total, there were 994 cases of rubella in Beijing Haidian District, with an average annual incidence of $1.81 / 100,000$ population. The majority of patients were at the age from 15 to 29 years old, accounting for $63.4 \%$. And the sex ratio of male-to-female was $1.45: 1$. The rubella had a feature of spatial aggregation and appeared in all the regions in Haidian District. In 2007, Haidian District was hitted by rubella with the highest incidence up to $8.37 / 100,000$, in the past 16 years. The peak incident of rubella was in May of that year, accounting for $74.8 \%$. The majority of rubella patients were students and employees (70.1\%) mainly due to the gathering. According to Joinpoint regression model, rubella would still exist in the next three years with 2-5 new cases per year.

Conclusions: The number of rubella in Haidian District showed a downshift trend from 2008 to 2014 and then a sporadic distribution till 2020. Yet this disease was not completely eliminated, it is quite impending to improve the awareness of rubella and their health literacy mentally and physically in the whole population by means of the policy issuing from government.

\section{Introduction}

Rubella, known as German measles or three-day measles, is an acute respiratory contagious disease caused by RNA virus (genus Rubivirus). It is usually a self-limited illness along with mild consequences, and difficult to discover in adults. What makes it terrible is that contagion may result in the cluster of spread before the onset of typical symptoms. Humans are the only known natural host of rubella as yet. The infected can spread through person-to-person contact. Pregnant women who got infection may bring devastating effects to their children, ranging from abortions to infants with congenital rubella syndrome (CRS), including visual or hearing impairment, heart disease, and so on ${ }^{[1]}$. Especially in the first trimester [2], the virus could pass through the placental barrier with dominant infection or not. Rubella occurs through all the year, exhibiting a fluctuating curve with high incidences in low-temperature weather. It could be epidemic widely every 6 to 9 years, even an outbreak.

Rubella was a severely contagious disease, spreading in a short time among the susceptible population. In the 1960s, there was a large-scale epidemic in the USA (United States of America). In order to control rubella and eliminate CRS, the USA began to implement combined rubella vaccine and got the favorable results ${ }^{[3]}$. In 2005, the World Health Organization announced a milestone event that the Americas region 
had eliminated rubella and CRS ${ }^{[4]}$. Immunization is the optimum way to prevent rubella currently. The European Vaccine Action Plan 2015-2020 (EVAP) proposed that 95\% inoculation rate could protect babies and the handicapped who cannot be vaccinated, ultimately to improve the health of the whole population. However, rubella is not completely wiped out in the other part of the world. Over 100,000 infants were born with CRS every year, and up to $80 \%$ of those from Africa and Asia ${ }^{[1]}$. Busy and crowding areas were still under higher risk of rubella ${ }^{[5]}$. Rubella is still an urgently public health issue to human. Effective vaccine did not fully cover the whole world, especially in developing countries and areas. Moreover, it is noteworthy of the underlying risk from global travel and mobility of population.

China has formally introduced the rubella-containing vaccine (RCV) into the Expanded Immunization Program (EPI) since $2008{ }^{[6]}$, while rubella cases were still occurring in the country. Even in 2018-2019,

the morbidity of rubella rose in China ${ }^{[7,8]}$. Beijing is a prosperous metropolis around the world, attracting the domestic and external population. The annual incidence of rubella manisfested that Beijing was still under the menace of RV in the other districts of adjacent to Haidian District, such as Xicheng District ${ }^{[9]}$ $(3.25 / 100,000)$ from 2003 to 2008, Shunyi District ${ }^{[10]}(14.82 / 100,000)$ in 2007 and $(15.08 / 100,000)$ in 2008 , and Changping District ${ }^{[11]}(10.465 / 100,000)$ from 2007 to 2011 . This study aimed to grasp the currently epidemic status of rubella in Beijing Haidian District from 2005 to 2020, providing the feedback on the prevention and control of rubella scientifically and effectively in the future.

\section{Methods}

\section{Source of information}

All the cases data were gathered by the legal infectious disease report cards from medical institutions in Beijing Haidian District during 2005 to 2020. Demographic data, including total population and regional distribution data, were from the Beijing Regional Statistical Annual, which belonged to the Beijing Municipal Bureau of Statistics. All the cases lived in Beijing Haidian District currently.

\section{Data inclusion}

The diagnosis of cases were verified by contagious specialists according to the serum rubella antibodies or the isolation of positive rubella virus in accordance with the Rubella Diagnostic Standards from the Ministry of Health of China. All the medical staffs professionally mastered the diagnostic standard and reporting procedures. All the confirmed cases in this study met the statutory infectious disease report. According to the age distribution of cases, there were four groups $(>15,15-29,30-49$, $>49$ years old). Since the incidence of rubella showed a sporadic situation since 2013, all the cases were divided into two timeframes including 2005-2012 and 2013-2020.

\section{Predictive model for Rubella}

The Joinpoint regression program (JRP) was used to fit the time-series of the number of new cases of rubella in Haidian District. As required, the value of the incidence of " 0 " was replaced by " 0.5 ". The 
Kolmogorov-Smirnov (K-S) corrected by Lilliefors was used to the test of normality of dependent variable.

\section{Statistical analysis}

The Microsoft Excel 2016 and SPSS 20.0 were used to sort and analyze the collected data. The descriptive epidemiological methods were used for the statistical description and analysis of rubella cases. The Chi-squared test was used to assess the difference in categorical variables. A two-sided test and $P<0.05$ were the criteria for statistical significance.

\section{Results}

\section{The epidemic situation of rubella}

From 2005 to 2020, a total of 994 cases of rubella were reported in Beijing Haidian District with an average annual incidence of $1.81 / 100,000$. In 2007, the rubella incidence rate was up to $8.37 / 100,000$, which was the highest incidence from 2005 to 2020 and up to 4.6 times higher than the average incidence. The rubella in Haidian District seemed gradually in the optimism since 2013. During 2005 to 2012 , the average incidence was $3.26 / 100,000$, and from then on it reduced to $0.47 / 100,000$ in the next eight years. In 2020, the incidence was down to $0.14 / 100,000$. In addition, there was zero death reported from cases, as shown in Fig.1.

\section{Seasonality analysis}

In the line chart from Fig2, the incidence of rubella showed an obviously seasonality fluctuation in Haidian District. The highest morbidity arose in May and reach the lowest in September. Rubella prevalence seemed to accompany along with spring weather (the averaged temperature in Haidian District: -2 to $8{ }^{\circ} \mathrm{C}$ ). Summing up the cases in peak months (March to May), there was a cumulative number of 577 cases, accounted for $58.1 \%$ of the total patients.

\section{Population distribution analysis}

There were 448 local patients and 546 non-native patients, accounting for $45.1 \%$ and $54.9 \%$ respectively in the past 16 years. The incidence of nonlocal patients was more than the locals with the statistically significant different $\left(X^{2}=9.662, P=0.002\right)$. The youngest baby of onset was only 27 days old, and the oldest was 90 years old. Over $1 / 2$ patients (63.4\%) were at the age of 15 to 29 years old. The male-tofemale ratio of cases was 1.45:1 (588/406) among the patients. There was a significant difference between the morbidity of gender $\left(\chi^{2}=33.324, P<0.000\right)$. There were 299 female patients in childbearing age (15 - 49 years old), accounting for $30.1 \%$. The high-risk incidence of crowd of rubella were students and employees, accounting for $29.9 \%$ and $40.2 \%$ relatively. Besides, male had a higher occurrence in these two groups as shown in Fig.3, Fig.4 and Table 1.

\section{Local distribution characteristics}


For ensuring the effective administration, the Haidian District was divided into 29 streets according to the cultural features and geographical location. While there was a significant regional difference the incidence $\left(\chi^{2}=750.000, P<0.000\right)$, it is obvious that rubella has a regional clustering character. Shangdi Street had the largest number of cases, with the regional morbidity of $9.2 / 100,000$. And the surrounding streets had relatively high incidences, such as Malianwa Street $(1.92 / 100,000)$, Xibeiwang Street $(1.54 / 100,000)$ and Qinglongqiao Street $(1.34 / 100,000)$. The top ten streets of rubella patients were the Shangdi Street, Xueyuan Road, Malianwa Street, Wanshou Road Street, Sijiqing Street, Xibeiwang Street, Qinghe Street, Zhongguancun Street, Qinglongqiao Street, Haidian Street, as shown in Fig. 5 and Table 2.

\section{The joinpoint regression analysis of the rubella}

The annual rubella cases obeyed normality distribution $(Z=0.877, P=0.426)$. The mean squared errors (MSEs) were 5.04 and 3.93, respectively, after the calculation by model $1 \& 2$ in JPR. The model 2 was chosen to estimate the critical point of epidemic trend. As it shown in Fig.6, there were two segment point which were 2007 and 2017 . The fitting regression equation is as follow:

$E\left[y_{i} \mid x_{i}\right]=\operatorname{EXP}\left(-2401.056874+1.197275^{\star} x_{i}-1.531075 *\left(x_{i}-2007\right)^{+}+0.841992 *\left(x_{i}-2017\right)^{+}\right.$. [If $\left(x_{i}-\tau_{k}\right)>0$, then $\left(x_{i}^{-}\right.$ $\left.\tau_{k}\right)^{+}=\left(x_{i}-\tau_{k}\right)$, otherwise $\left(x_{i}-\tau_{k}\right)^{+}=0, y_{i}$ is the number of patients, $x_{i}$ is the year, $\tau_{k}$ is the change point]. According to the Joinpoint regression model, rubella wasn't eradicated in Beijing Haidian District, and in the next three years there would be 2, 3 and 5 new cases, respectively. As shown in Fig7, the female in Haidian District would have a higher potential risk in suffering rubella than male.

\section{Discussion}

The prevalence of rubella in different regions would come out with a variety of consequences ${ }^{[12]}$. This study found that the incidence of rubella in Beijing Haidian District was 1.81/100,000, from 2005 to 2020. It is lower than that of the other District in Beijing ${ }^{[9-11]}$, which might be related with its booming economy and higher living standards. However, rubella didn't eliminate in Haidian District. Rubella has general population susceptibility, the free rubella vaccine program aim to the migrant workers has a low inoculation rate, which is accordance with the result. More than half of patients (54.9\%) are external population, as the research showed. In terms of occupation, students and employees had the higher morbidity. Overcrowding population may bring a higher risk to virus transmission, and result in an adverse incidence of rubella further. Therefore, it is suggested that strengthening the monitoring of health issues, can prevent the outbreak of this disease effectively in public places, especially in high risk population like the intense crowds and the migrant.

With the gradual development in the living and sanitary conditions, rubella has been well controlled through vaccine immunization. As the literature described, when the rubella outbreaks, diverse RCVs could be able to provide $90 \%-100 \%$ effective protection ${ }^{[13]}$. According to the WHO, large-scale rubella vaccination has helped lots of countries significantly reduce or virtually eliminate rubella and CRS ${ }^{[12]}$. However, there are still some countries and regions, including developed countries, being threatened by 
the spread and epidemic of rubella, and even underlying the tendency to outbreak ${ }^{[12,14]}$. In September 2006, Beijing, as the first city in China, started to introduce the trivalent measles, mumps and rubella vaccine (MMR) into type I vaccine, which was given to target children aged 1.5 and 6 years free of charge ${ }^{[10]}$. With the effective penetration of the EPI, the dynamics of virus transmission have changed, main susceptible group of rubella was rather the higher age group, than the preschool children. This trend has also been observed in other Chinese cities, such as the Fengxian District of Shanghai ${ }^{[15]}$ and the Zhoangshan city of Guangdong ${ }^{[16]}$. This study also manifested the same trend, people aged 15 to 29 had higher incidence.

What deserves more attention is that pregnant women with viral infection can often cause death or CRS to the fetus ${ }^{[17]}$. Reportedly, there are still CRS kids born without a healthy body nowadays ${ }^{[18]}$. As researches suggested that rubella infection rates are higher in urban women than in rural women, in addition, childbearing age women have a higher risk of rubella infection ${ }^{[19,20]}$. Some European countries, such as Finland, Iceland, Norway, and Sweden, have implemented rubella vaccination unremittingly, which has successfully blocked its transmission and eventually eliminated CRS. While, the coverage of rubella vaccine in developing countries is not comprehensive, which will put them under the threat of rubella and even an aggravate burden to society ${ }^{[21]}$. One of the studies found that vaccination of school girls not only could reduce cases of rubella, but also effectively lower the incidence of $\mathrm{CRS}^{[22]}$. Other research also suggested that the majority of CRS heart diseases can be avoided through vaccinating adults and kids ${ }^{[4]}$. In this research, the female in Beijing Haidian District seemingly would have a higher potential threat by rubella. Screening and protecting of women in reproductive age is the key to prevent CRS, and it is also a response to the national policy of eugenic. Since more and more travelling and migration, rubella has the possibility of danger been imported into areas where rubella is nonexistent, leading to outbreaks and the reappearance of transmission. Meanwhile, a further consideration is the impact of the current COVID-19 pandemic on vaccinations. The preliminary data registered in the USA indicate that a general decline in global immunization coverage is expected ${ }^{[23]}$. There are still some vaccination gap in the population ${ }^{[7-8]}$. Given that the population's behavioral patterns, low awareness of rubella and some individual reasons for vaccine hesitant, the primary challenge is to fill the gap by encouraging appropriate newborns and susceptible population to go to hospital to receive a serum antibody test and vaccinations, finally improve the health of the population. The further public strategies of rubella should keep abreast with the situation to reduce the incidence of rubella and CRS effectively.

\section{Conclusion And Recommendations}

In conclusion, the incidence of rubella in Beijing Haidian District is under control, while is not completely eliminated. While there were more male rubella patients, it is equally important that the female might under the latent higher risk. According to the current status, it is wise to confirm the susceptible group and implement the vaccine coverage. There is no doubt that improving and perfecting the sanitation system to control and eliminate the rubella should be stepped up continuously, which would bring us a healthier country. 


\section{Abbreviations}

Rubella virus, RV, Congenital rubella syndrome, CRS, Rubella-containing vaccines, RCVs, the European Vaccine Action Plan 2015-2020, EVAP.

\section{Declarations}

\section{Ethical approval and consent to participate}

According to National Health Commission of the People's Republic of China, the data involved in this study did not include any data of patients' personal information, including name, identifying information, exact address, telephone number, etc. This study mainly focused on aggregating the available data, so consent to participate and ethics approval are unnecessary.

\section{Consent for publication}

Not applicable.

\section{Availability of data and materials}

Data of the study was not publicly available, the datasets used and analysed during the current study are available from the corresponding author on reasonable request.

\section{Competing interests}

The authors declare that they have no competing interests.

\section{Funding Statement}

This work was supported by Natural Science Foundation of Guangdong Province of China (2021A1515011220), Administration of Traditional Chinese Medicine of Guangdong Province of China (20211008), National Natural Science Foundation of China (81473014), Top Young Talents of Guangdong Hundreds of Millions of Projects (87316004) and Outstanding Young Talent of Double Hundred Talents Plan in Jinan University.

\section{Authors' contributions}

SY and XP interpreted the data and wrote the manuscript. FW, CZ and LZ collected and collated data. JY and HL revised the work. The study on which this paper was conceived and designed by ZW and WZ. All authors have commented on drafts of the paper and approved this submitted version.

\section{Acknowledgements}

Not applicable. 


\section{References}

1. Reef S E, Strebel P, Dabbagh A, et al. Progress toward control of rubella and prevention of congenital rubella syndrome--worldwide. Journal of Infectious Diseases. 2009, (suppl_1): 1307-1310. DOI: 10.1093/infdis/jir155.

2. Plotkin S A. Congenital Rubella Syndrome in Late Infancy. Jama the Journal of the American Medical Association. 1967, 200(6): 435-441. DOI: 10.1001/jama.200.6.435.

3. Berger B E, Navar-Boggan A M, Omer S B. Congenital rubella syndrome and autism spectrum disorder prevented by rubella vaccination - United States, 2001-2010. Bmc Public Health. 2011, 11(1):340-340. DOI: 10.1186/1471-2458-11-340.

4. Centers for Disease Control and Prevention (CDC). Progress toward elimination of measles and prevention of congenital rubella infection--European region, 1990-2004. MMWR Morb Mortal Wkly Rep. 2005, 54(7): 175-178.

5. Taishi K, Hyojung L, Ryo K, et al. Identifying geographic areas at risk of rubella epidemics in Japan using seroepidemiological data. 2021, 102: 203-211. DOI: 10.1016/J.IJID.2020.09.1458.

6. Su Q, Ma C, Wen N, et al. Epidemiological profile and progress toward rubella elimination in China. 10 years after nationwide introduction of rubella vaccine. Vaccine, 2018. DOI: 10.1016/j.vaccine.2018.03.013.

7. Miaomiao Z, Qiru S, Chao M, et al. Epidemiological characteristics of rubella public health emergency events in China, 2005-2016. Chinese Journal of Vaccines and Immunization. 2019, 25(3): 243-247.

8. Yuanqiu L, Chao M, Lixin H, et al. Epidemiology of rubella in China, 2018-2019. Chinese Journal of Vaccines and Immunization. [2021-01-25]: 1-8 .

http://kns.cnki.net/kcms/detail/11.5517.r.20201216.1108.005.html.

9. Qing W, Mu S, Changhong C, et al. ANALYSIS ON RUBELLA EPIDEMIOLOGICAL CHARACTERISTICS AND CONTROLLING MEASURES IN XICHENG DISTRICT OF BEIJING. Modern Preventive Medicine. 2011, 38(10): 1945-1947.

10. Lei X, Fengshuang W, Dan W, et al. Epidemiological characteristics of rubella in shunyi district, Beijing in 2007 - 2008. Capital Journal of Public Health. 2009, 3(3): 134-136.

11. Xiuyun W, Tao W, Haihong W, et al.. Haihong, Analysis on the epidemic characteristics of rubella in changping district, Beijing from 2007 to 2011. Practical Preventive Medicine. 2013, 20(6): 692-693.

12. Yan $L$, Jing $M$, Dapeng $Y$, et al. WHO. Rubella vaccines: WHO position paper. CHINESE JOURNAL OF VACCINES AND IMMUNIZATION. 2011, 17(6): 565-568.

13. Chenggang W. Immune prevention of rubella and congenital rubella syndrome. South China J Prev Med. 2011, 37(5):77-79.

14. Yoshio Mori. Summary of the special symposium 'Towards Elimination of Rubella'. Vaccine. 2020, 38(40)6344-6345.

15. JRui-ping L, Cai-hong G, Ke-hua Y, et al. pidemiological characteristics analysis of rubella and discussion of its control strategies in Fengxian District of Shanghai, 2003-2015. Shanghai Journal of 
Preventive Medicine, 2017, 29(9): 698-701+706.

16. En-miao H, Cuiling W, Man W. Epidemic characteristics of rubella in Zhongshan City of Guangdong, 2010-2019. Modern Preventive Medicine. 2020, 47(17): 3096-3099.

17. Changhong C, Yan D, Advances in epidemiology of congenital rubella syndrome. DISEASE SURVEILLANCE. 2012, 27(11): 918-922.

18. Das Dipankar et al. Rubella eye disease: A clinicopathological case report. Indian Journal of Ophthalmology - Case Reports. 2021, 1(2): 317-319.

19. Suling L, Yan W, Guoping Y, et al., Investigation of rubella antibody level in newly married women and evaluation of rubella vaccine immune effect. Chinese Journal of Vaccines and Immunization. 2004, 10(1): 15.

20. Feiyun $Z$, Jimei $D$, Yan $H$, et al. A study of rubella virus infection during pregnancy. Chin $\mathrm{J}$ Obstet Gyneco. 2002, 37(7): 391-394.

21. Andrus, J K, Dietz V, John F, et al. Accelerating policy, deployment, and access to new and underutilized vaccines in developing countries. Harvard Health Policy Rev. 2006, 7(2): 12.

22. Tookey P A , Peckham C S . Surveillance of congenital rubella in Great Britain, 1971-96. Bmj. 1999, 318(7186):769-770.

23. Bramer CA, Kimmins LM, Swanson R, et al. Decline in Child Vaccination Coverage During the COVID19 Pandemic - Michigan Care Improvement Registry, May 2016-May 2020. MMWR Morb Mortal Wkly Rep. 2020,69(20):630-631.

\section{Tables}

Table 1 General demographic characteristics of rubella cases in Beijing Haidian District from 2005 to 2020 


\begin{tabular}{|c|c|c|c|c|}
\hline \multirow[t]{2}{*}{ characteristic } & \multicolumn{2}{|l|}{ Year } & \multirow[t]{2}{*}{$n$} & \multirow[t]{2}{*}{$\%$} \\
\hline & $2005-2012$ & $2013-2020$ & & \\
\hline \multicolumn{5}{|l|}{ Gender } \\
\hline Male & 508 & 80 & 588 & 59.1 \\
\hline Female & 352 & 54 & 406 & 40.8 \\
\hline \multicolumn{5}{|l|}{ Native place } \\
\hline Local & 377 & 71 & 448 & 45.1 \\
\hline Non-native & 483 & 63 & 546 & 54.9 \\
\hline \multicolumn{5}{|l|}{ Age (year) } \\
\hline$<15$ & 195 & 30 & 225 & 22.6 \\
\hline $15-29$ & 556 & 85 & 634 & 63.4 \\
\hline $30-49$ & 101 & 27 & 128 & 12.8 \\
\hline$>49$ & 8 & 2 & 10 & 1.2 \\
\hline \multicolumn{5}{|l|}{ Occupation } \\
\hline Children living at home & 59 & 22 & 81 & 8.1 \\
\hline Kindergarten children & 51 & 5 & 56 & 5.6 \\
\hline Students & 266 & 32 & 298 & 29.9 \\
\hline Employee & 341 & 59 & 400 & 40.2 \\
\hline Unemployed & 87 & 16 & 103 & 10.3 \\
\hline Unknown & 56 & 0 & 56 & 5.6 \\
\hline Total & 860 & 134 & 994 & 100.0 \\
\hline
\end{tabular}

Table 2 Incidence distribution of rubella in streets of Beijing Haidian District from 2005 to 2020 


\begin{tabular}{|c|c|c|c|c|c|}
\hline \multirow[t]{2}{*}{ Street } & \multicolumn{2}{|l|}{ Year } & \multirow[t]{2}{*}{$n$} & \multirow[t]{2}{*}{$\%$} & \multirow[t]{2}{*}{ Morbidity $(/ 100,000)$} \\
\hline & 2005-2012 & $2013-2020$ & & & \\
\hline Wanshou Road street & 52 & 7 & 59 & 5.94 & 1.72 \\
\hline Yongding Road street & 23 & 2 & 25 & 2.52 & 0.73 \\
\hline Yangfangdian street & 16 & 6 & 22 & 2.21 & 0.64 \\
\hline Ganjiakou street & 15 & 3 & 18 & 1.81 & 0.52 \\
\hline Balizhuang street & 25 & 4 & 29 & 2.92 & 0.84 \\
\hline Zizhuyuan street & 37 & 5 & 42 & 4.23 & 1.22 \\
\hline Beixiaguan street & 32 & 6 & 38 & 3.82 & 1.11 \\
\hline Beitaipingzhuang street & 28 & 4 & 32 & 3.22 & 0.93 \\
\hline Xueyuan Road sreet & 62 & 8 & 70 & 7.04 & 2.04 \\
\hline Zhongguancun street & 45 & 5 & 50 & 5.03 & 1.46 \\
\hline Haidian street & 42 & 3 & 45 & 4.53 & 1.31 \\
\hline Qinglong Bridge street & 38 & 8 & 46 & 4.63 & 1.34 \\
\hline Qinghuayuan street & 26 & 2 & 28 & 2.82 & 0.82 \\
\hline Yanyuan street & 12 & 3 & 15 & 1.51 & 0.44 \\
\hline Xiangshan street & 13 & 1 & 14 & 1.41 & 0.41 \\
\hline Qinghe street & 36 & 6 & 42 & 4.23 & 1.22 \\
\hline Huayuan Road street & 22 & 5 & 27 & 2.72 & 0.79 \\
\hline Xisanqi street & 20 & 2 & 22 & 2.21 & 0.64 \\
\hline Malianwa street & 60 & 6 & 66 & 6.64 & 1.92 \\
\hline Tiancun Road street & 24 & 7 & 31 & 3.22 & 0.90 \\
\hline Shangdi street & 76 & 18 & 94 & 9.46 & 2.74 \\
\hline Wanliu area & 5 & 3 & 8 & 0.80 & 0.23 \\
\hline Dongsheng area & 6 & 0 & 6 & 0.60 & 0.17 \\
\hline Shuguang street & 18 & 5 & 23 & 2.31 & 0.67 \\
\hline Wenquan town & 10 & 1 & 11 & 1.11 & 0.32 \\
\hline Sijiqing town & 51 & 4 & 55 & 5.53 & 1.60 \\
\hline Xibeiwang town & 47 & 6 & 53 & 5.33 & 1.54 \\
\hline
\end{tabular}




\begin{tabular}{|llllll|} 
Sujiatuo town & 6 & 2 & 8 & 0.80 & 0.23 \\
\hline Shangzhuang town & 6 & 2 & 8 & 0.80 & 0.23 \\
\hline Unknwon & 6 & 0 & 6 & 0.60 & 0.17 \\
\hline Total & 860 & 134 & 994 & 100.00 & 1.81 \\
\hline
\end{tabular}

Figures

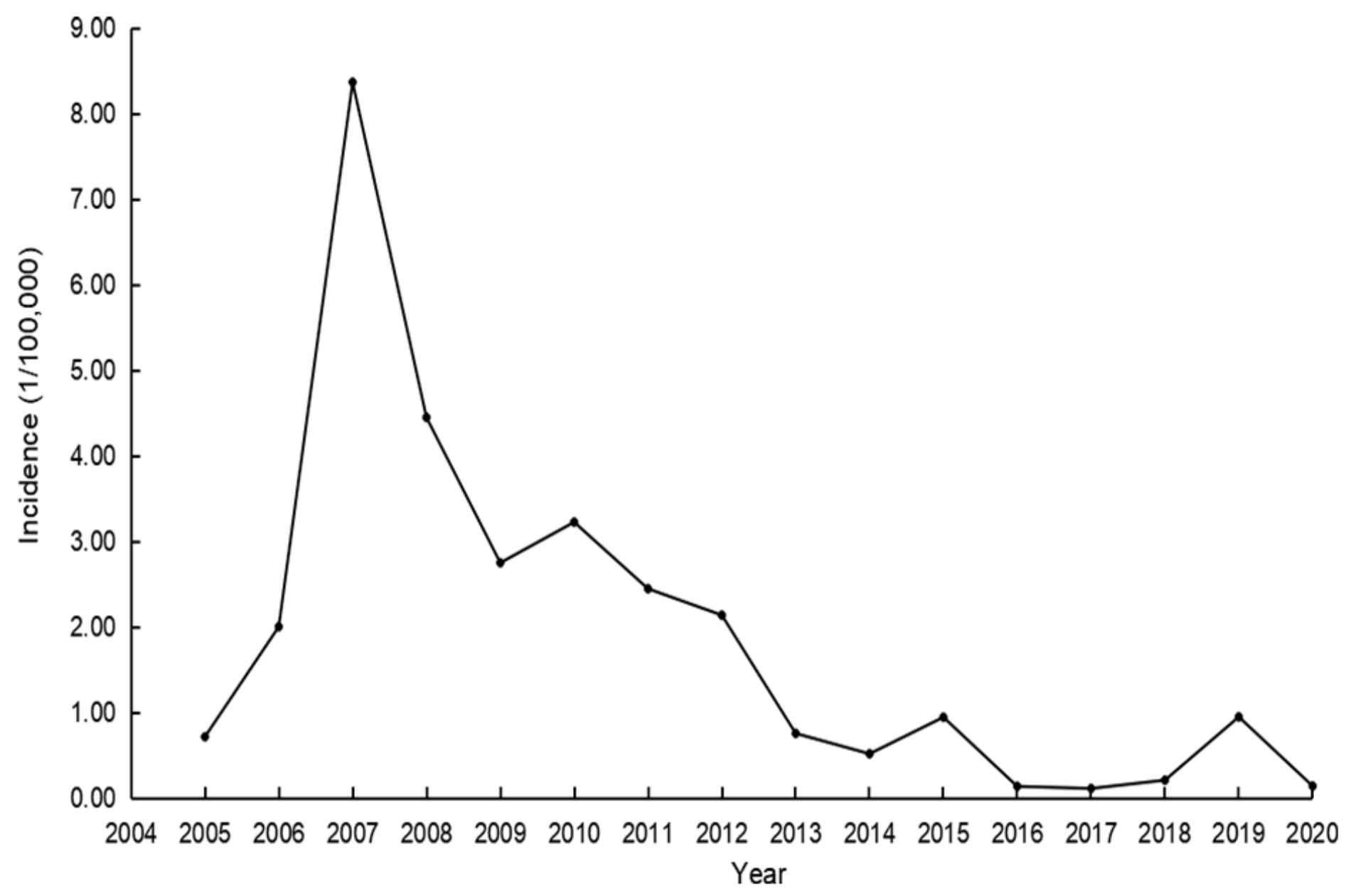

Figure 1

Distribution of incidence of rubella in Beijing Haidian District from 2005 to 2020 


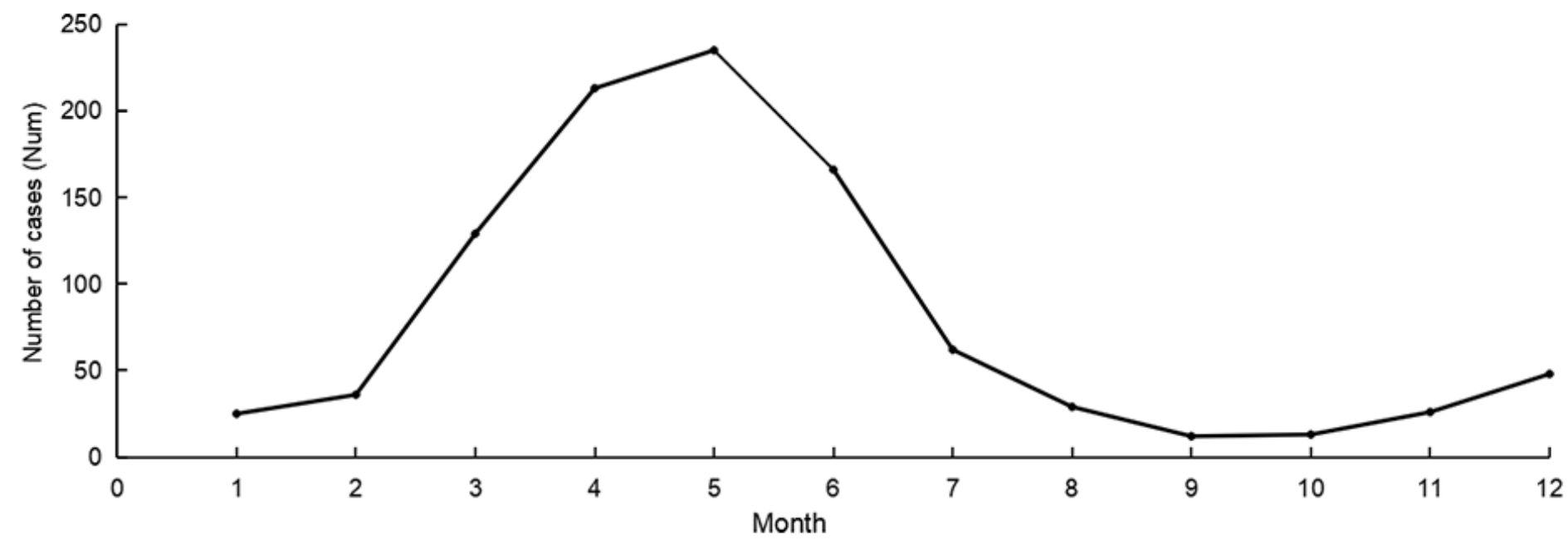

Figure 2

Distribution of incidence of rubella in Beijing Haidian District from 2005 to 2020 


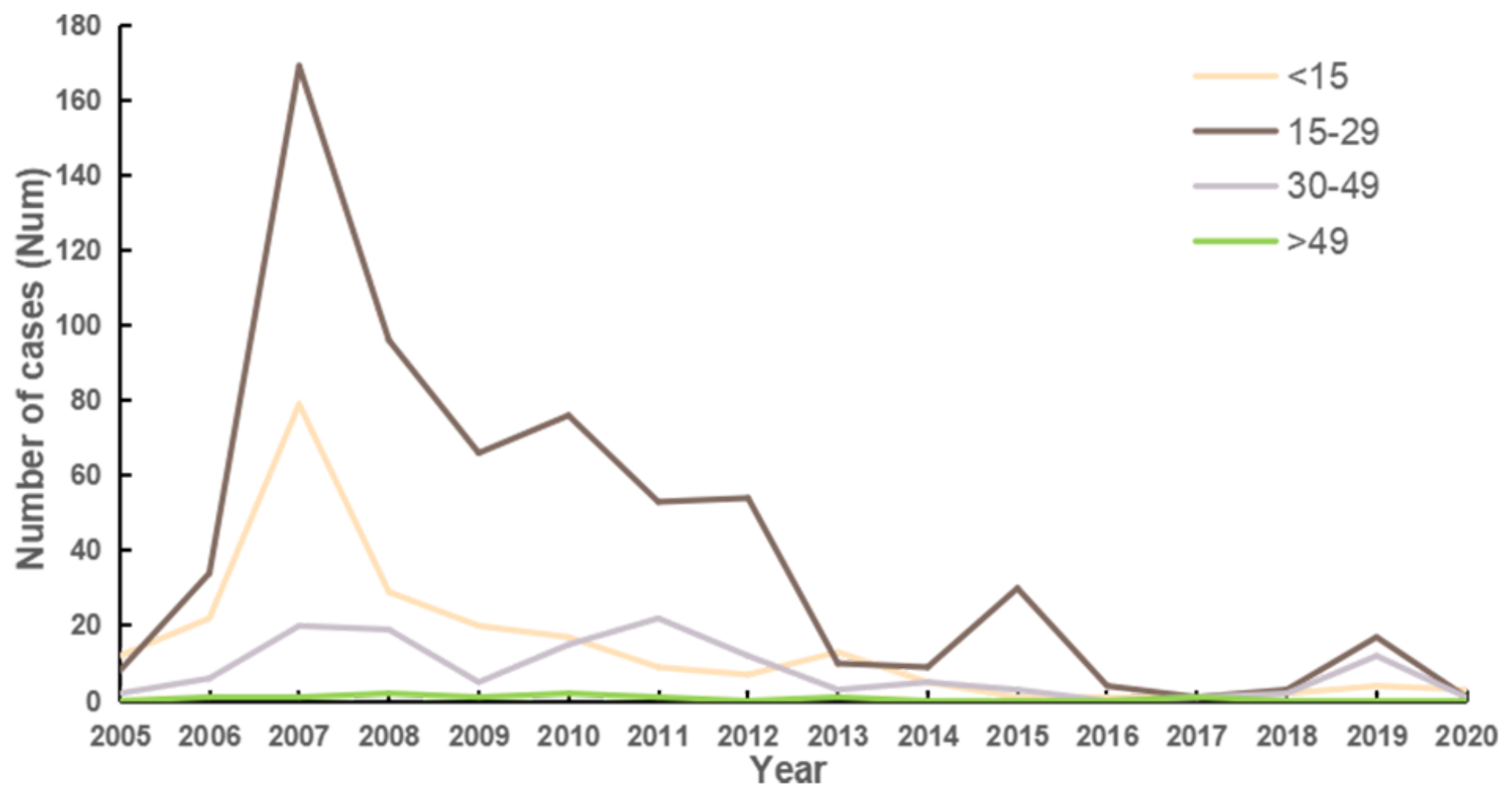

Figure 3

Distribution of incidence of rubella sorted by age in Beijing Haidian District from 2005 to 2020 


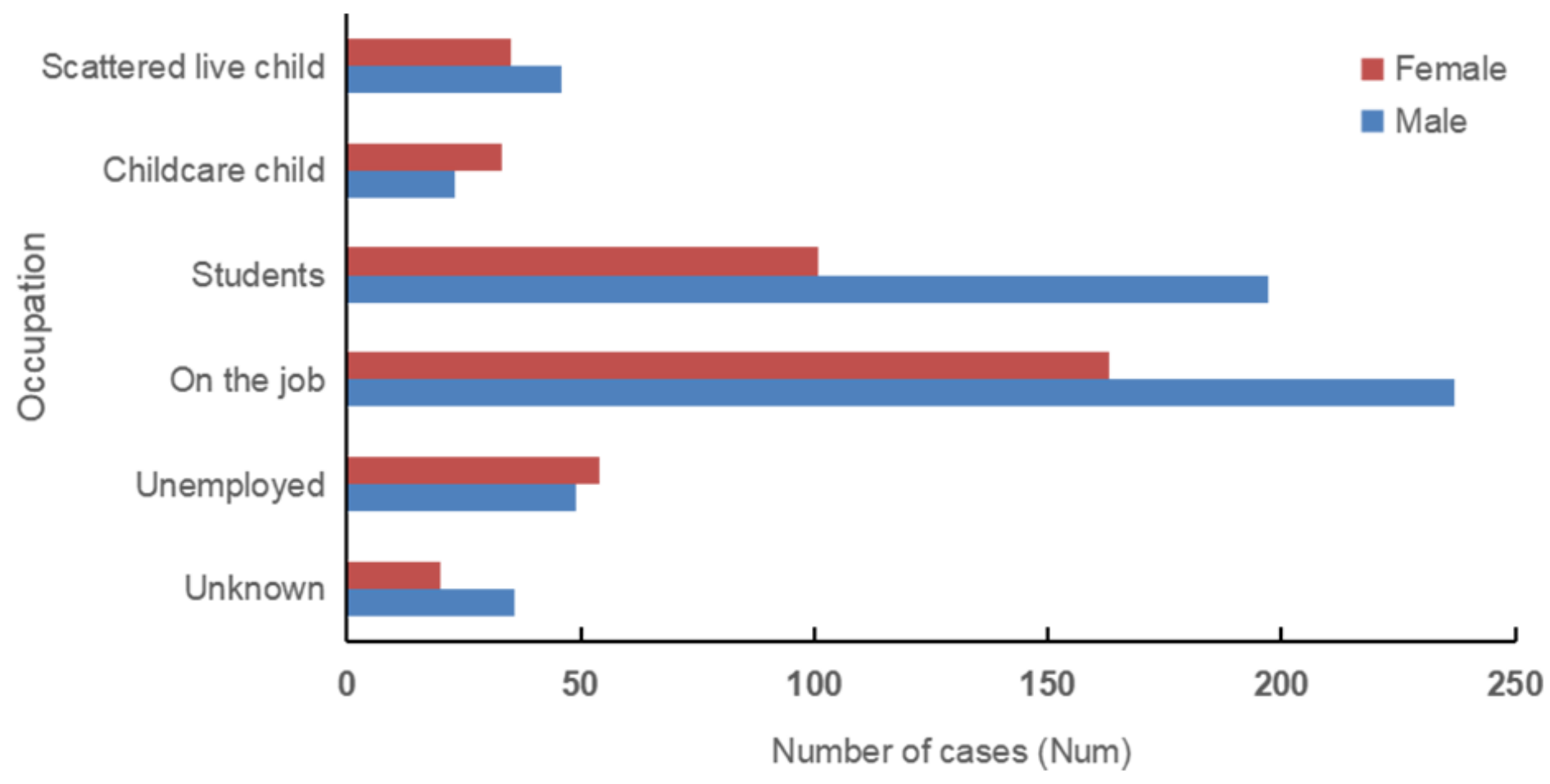

\section{Figure 4}

Distribution of incidence of rubella sort by occupation between gender in Beijing Haidian District from 2005 to 2020 


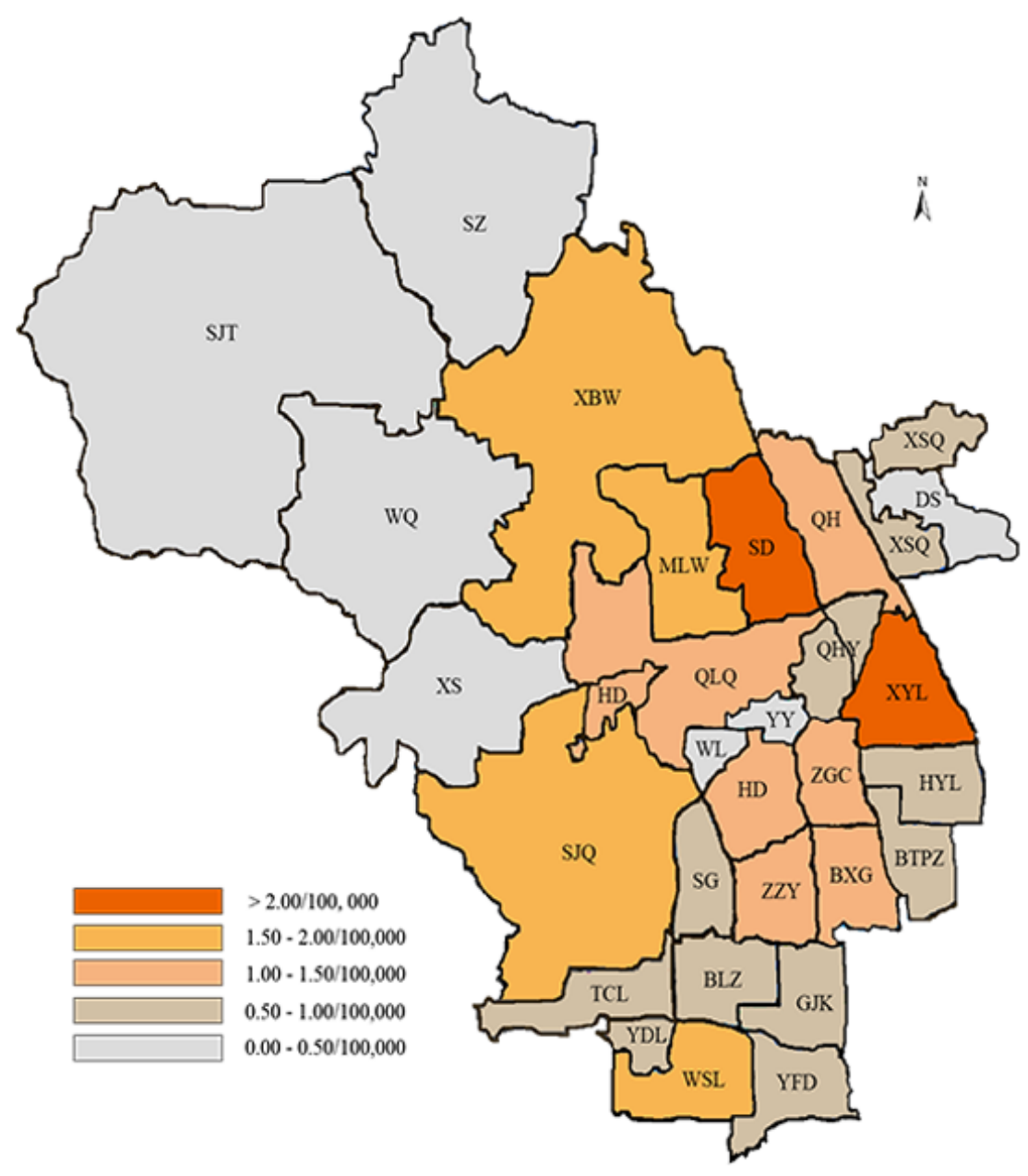

Figure 5

Incidence distribution of rubella in streets of Beijing Haidian district from 2005 to 2020 Haidian District: Wanshou Road (WSR), Yongding Road (YDR), Yangfangdian (YFD), Ganjiakou (GJK), Balizhuang (BLZ), Zizhuyuan (ZZY), Beixiaguan (BXG), Beitaipingzhuang (BTPZ), Xueyuan Road (XYR), Zhongguancun(ZGC), Haidian (HD), Qinglongqiao (QLQ), Qinghuayuan (QHY), Yanyuan (YY), Xiangshan (XS), Qinghe (QH), Huayuan Road (HYR), Xisanqi (XSQ), Malianwa (MLW), Tiancun Road (TCR), Shuguang (SG), Shangdi (SD), Wanliu (WL), Dongsheng (DS), Wenquan (WQ), Sijiqing (SJQ), Xibeiwang (XBW), Sujiatuo (SJT), Shangzhuang (SZ). Note: The designations employed and the presentation of the material on this map do not imply the expression of any opinion whatsoever on the part of Research Square concerning the legal status of any country, territory, city or area or of its authorities, or concerning the delimitation of its frontiers or boundaries. This map has been provided by the authors. 


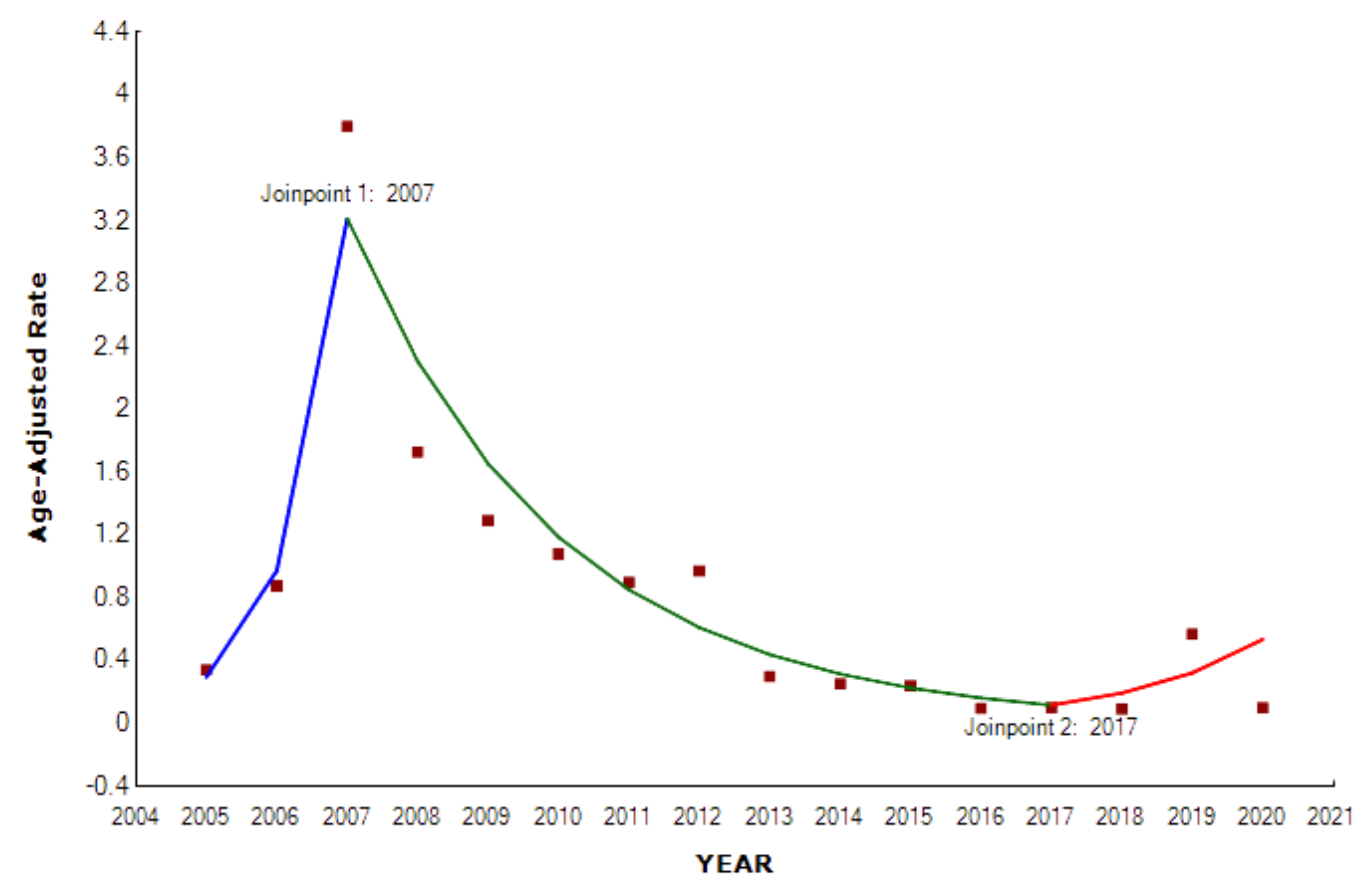

- Indicates that the Annual Percent Change (APC) is significantly different from zero at the alpha $=0.05$ level. Final Selected Model: 2 Joinpoints.

\section{Figure 6}

Joinpoint trend change of annual incident Beijing Haidian district from 2005 to 2020
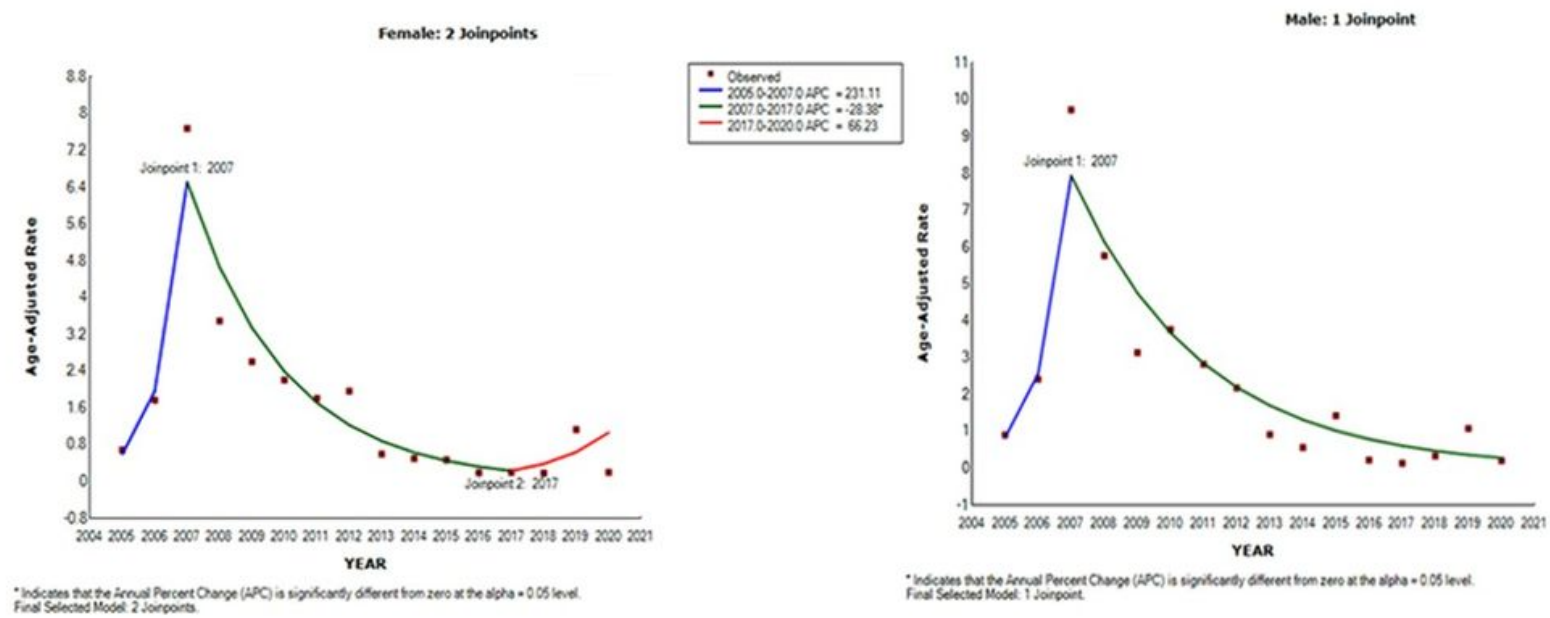

\section{Figure 7}

Joinpoint trend change of rubella between different sex in Beijing Haidian District from 2005 to 2020 